\title{
Lobster Dysgeusia
}

Charles F. Guardia ${ }^{1 *}$, Timothy G. Lukovits ${ }^{2}$ and Richard P. Goddeau ${ }^{2}$

${ }^{1}$ Section of Sleep Medicine, Dartmouth Hitchcock Medical Center, USA

${ }^{2}$ Department of Neurology, Dartmouth Hitchcock Medical Center, USA

Received: October 31, 2013; Accepted: January 15, 2014; Published: January 18, 2014

"Corresponding author: Charles F. Guardia, Section of Sleep Medicine, Dartmouth Hitchcock Medical Center, One Medical Center Drive, Lebanon, NH 03756, USA, Tel: 603-650-3630; E-mail: Charles.F.Guardia@hitchcock.org

Keywords: Dysgeusia; Thalamus; Stroke

\section{Case Presentation}

A 61 year old woman developed acute onset horizontal diplopia, a left sided Horner's syndrome and bilateral vertical gaze palsy. Brain MRI showed an acute infarct in the right medial thalamus (Figure 1). Lobster, which was previously enjoyable,

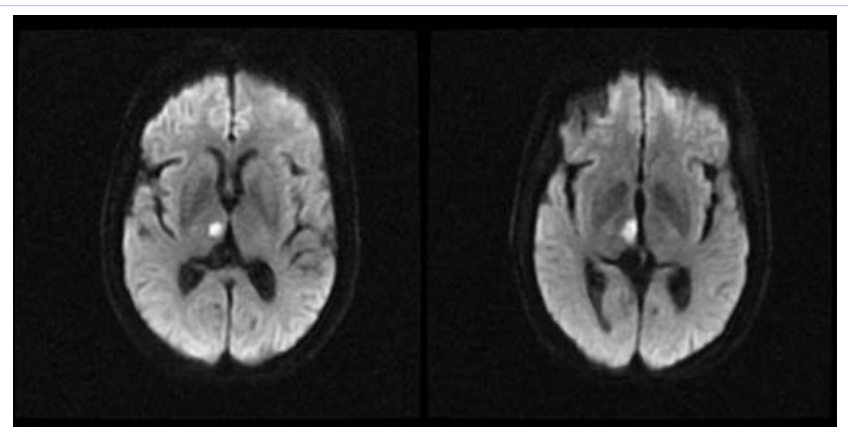

Figure 1: Diffusion weighted imaging showing an acute infarct in the right medial thalamus. tasted poorly and lost its appeal approximately two weeks following the infarct. Enjoyment of other food was unimpaired. Olfaction remained intact. No new or concurrent medications could be implicated in engendering such symptoms, and the patient had no history of exposure to chemotherapeutic agents. Taste to salt sweet on the anterior and posterior aspects of all regions of the tongue remained intact. She was also able to discern salt water, sugar water, lemon juice and chocolate when presented to her in a blinded fashion. The ventroposteromedial nuclei are the somatosensory relays for taste, with gustatory sensation mediated by the parvicellular division of the VPM $[1,2]$. To our knowledge this is first description of a unilateral right sided thalamic lesion altering the hedonic perception of once pleasant gutastory stimuli.

\section{References}

1. Schmahmann JD (2003) Vascular syndromes of the thalamus. Stroke 34(9): 2264-2278.

2. Sela L, Sacher Y, Serfaty C, Yeshurun Y, Soroker N, et al. (2009) Spared and impaired olfactory abilities after thalamic lesions. J Neurosci 29(39): 12059-12069. 